\title{
Tuberculosis miliar o diseminada
}

\author{
Miliary or disseminated tuberculosis
}

Luz Fernanda Sua V., MD., PhDc. ${ }^{(1)}$; Liliana Fernández T., MD. ${ }^{(2)}$

(1)Anatomía Patológica y Patología Clínica, Departamento de Patología y Medicina de Laboratorio, Patología pulmonar. Ciencias Biomédicas. Línea de investigación Biomédica en Tórax, Fundación Valle del Lili. Profesora Clínica Asistente, Facultad de Ciencias de la Salud, Universidad Icesi. Cali, Colombia.

${ }^{(2)}$ Medicina Interna, Neumología, Neumología intervencionista. Línea de Investigación Biomédica en Tórax. Fundación Valle del Lili. Profesora Clínica Asociada, Facultad de Ciencias de la Salud, Universidad Icesi. Cali, Colombia.

Correspondencia: Luz Fernanda Sua, correos electrónicos: lufer24@hotmail.com, lfsua@fcvl.org

Recibido: 15/04/15, Aceptado: 30/04/15.

\section{Introducción}

La infección por M. tuberculosis es muy frecuente en nuestro medio. Entre tanto, la tuberculosis miliar o diseminada aumenta en los grupos de pacientes con compromiso de la respuesta inmunológica, como infección por el VIH, SIDA, diabetes mellitus, alcoholismo, cirrosis hepática, tratamiento inmunosupresor, insuficiencia renal crónica y neoplasias malignas.

\section{Definición}

En la tuberculosis diseminada ocurre el paso de bacilos a la sangre y así a órganos como médula ósea, riñón, coroides, glándulas suprarrenales, ganglios linfáticos, hígado, bazo, trompas de Falopio, próstata, cordón espermático o endometrio. El compromiso de páncreas, tiroides, corazón y músculo estriado es infrecuente.

\section{Etiología}

La especie Hominis del Mycobacterium tuberculosis se transmite a través de las microgotas de estornudos o tos.

\section{Lavado broncoalveolar}

En los pacientes con tuberculosis miliar, la severidad de la enfermedad en algunos casos o la pobre producción de secreciones en otros, hacen poco probable la recuperación de bacilos para el diagnóstico en muestras de esputo, por lo tanto el lavado broncoalveolar adquiere gran importancia. La cantidad de bacilos recuperada puede ser escasa, de modo que la coloración de Ziehl-Nielsen con frecuencia es negativa, así que se complementa el estudio con la tinción de auramina rodamina y con GeneXpert, que detecta secuencias de ADN específico del Mycobacterium tuberculosis y da información sobre la resistencia a la Rifampicina medicamento muy importante en el tratamiento. Además, el lavado broncoalveolar proporciona información sobre los diagnósticos diferenciales y permite el cultivo de la muestra para intentar el diagnóstico definitivo.

\section{Descripción macroscópica}

Existen cambios macroscópicos que permiten determinar la sospecha diagnóstica desde la pieza quirúrgica; usualmente en el área del parénquima comprometido suele observarse material grumoso y blanquecino nodular entre 2 y $4 \mathrm{~mm}$.

\section{Descripción microscópica}

Desde el punto de vista histológico se observa inflamación granulomatosa crónica con una zona central de necrosis caseosa, rodeada de células gigantes de 
Langhans, epitelioides y linfocitos. La necrosis caseosa es importante para orientar el diagnóstico. Esta es causada por enzimas líticas y radicales libres producidos por los macrófagos activados. La acción citotóxica de los linfocitos TCD8+ al reconocer antígenos de las micobacterias expresados en moléculas del CMH de Clase 1 y la falta de riego sanguíneo en el sector central del granuloma que es avascular, desarrollan la necrosis, que a su vez es una combinación de necrosis coagulativa (por desnaturalización proteica, fundamentada en la hipoxia) y necrosis licuefactiva (que obedece a la acción lítica enzimática y citolítica celular). E1 fenómeno de lisis no es completo a raíz de los lípidos complejos y ceras que la bacteria tiene en su pared. Estos y sus residuos contribuyen también al aspecto macroscópico grumoso, blanco amarillento del caseum y hacen a este tipo de necrosis, exclusiva para esta enfermedad (figura 1).

\section{Coloración histoquímica e inmunofluorescencia}

El bacilo presenta una membrana cérea impermeable a la mayor parte de los colorantes (ácidos y alcoholes), si bien se tiñe de rojo con el método Ziehl-Nielsen (figura 1) y es observable al microscopio de fluorescencia previa tinción con auramina.

\section{Diagnósticos diferenciales}

Sarcoidosis e infecciones micóticas como histoplasmosis o coccidioidomicosis o lesión neoplásica maligna.

\section{Sugerencias}

- En el análisis de la biopsia es importante conocer el contexto clínico del paciente y sus imágenes

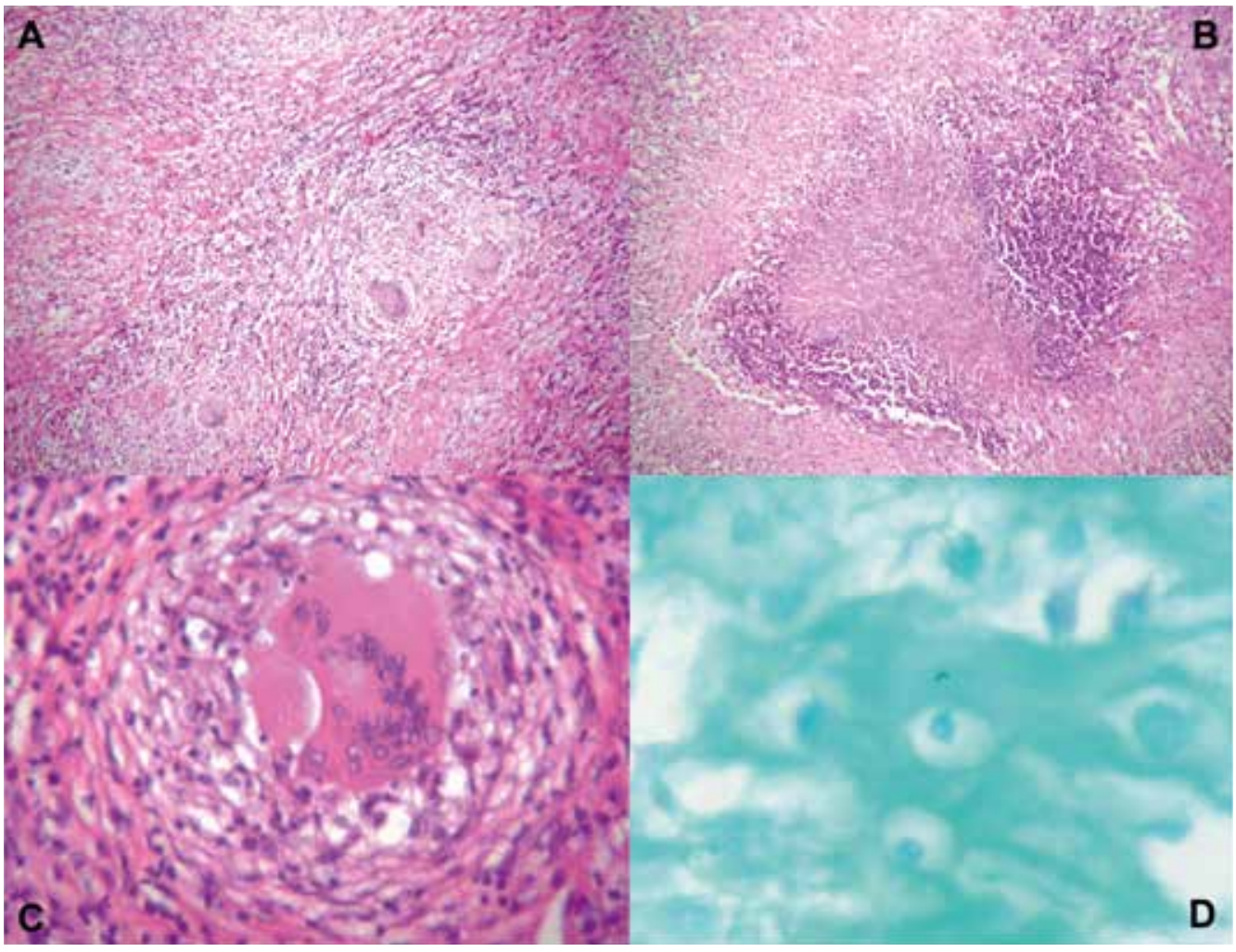

Figura 1. A, B y C. Coloración de hematoxilina/eosina en la que se observan granulomas con presencia de células gigantes de tipo Langhans y focos de necrosis caseosa central. D. Coloración de BK positiva para bacilos ácido-alcohol resistentes. 
radiológicas, pues el manejo de las piezas quirurgicas o biopsias en estos casos debe hacerse con altas medidas de bioseguridad para el personal de patología y microbiología.

- Cuando se tiene necrosis caseosa, el primer diagnóstico a descartar en tuberculosis son patologías como la sarcoidosis, que producen necrosis atípica y constituyen diagnósticos de exclusión.

\section{Conflictos de interés}

Los autores declaran no tener conflictos de interés.

\section{Bibliografía}

1. Jeong YJ, Lee KS. Pulmonary tuberculosis: up-to-date imaging and management. AJR Am J Roentgenol. 2008;191(3):834-44.

2. Bustamante-Rengifo JA, Sua LF, Astudillo M, et al. Solitary intracranial tuberculoma mimicking a malignant tumor in a patient without tubercular lesion or a history of disease: A case report. Bosn J Basic Med Sci. 2013;13(2):129-33.

3. Kumar A, Kapoor VK, Behari A, et al. Splenic tuberculosis in an immunocompetent patient can be managed conservatively: a case report. Gastroenterol Rep. 2015;1-3. 